\title{
Orthographic and phonological computation in visual word recognition: Evidence from backward masking in Hebrew
}

\author{
RAM FROST and OSNAT YOGEV \\ Hebrew University, Jerusalem, Israel
}

\begin{abstract}
We employed the backward masking paradigm to map the early computation involved in the perception of printed words in Hebrew. By independently manipulating orthographic and phonological overlap between targets and masks, we examined whether orthographic and phonological structure imposes late or early constraints on lexical access. The results demonstrated that the probability of reinstating a masked target depended on both the orthographic and the phonological overlap between the target and the mask. However, whereas phonemic structure seems to constrain lexical access only at short exposure durations, orthographic overlap also exerts its influence at longer durations.
\end{abstract}

It is now well established that the processing of printed words involves some form of phonological computation (e.g., Berent \& Perfetti, 1995; Coltheart, Curtis, Atkins, \& Haller, 1993; Lukatela \& Turvey, 1990, 1994a, 1994b; Van Orden, Pennington, \& Stone, 1990; and see Frost, 1998, for a review). One important empirical question concerns the time course and characteristics of the computed phonological code.

A prominent source of evidence for mapping the computations involved in visual word recognition focuses on the presentation of printed words at brief exposure durations (e.g., Humphreys, Evett, \& Quinlan, 1990). Within this experimental approach, both the forward and the backward masking paradigms have provided compelling results. In the forward masking technique (e.g., Forster \& Davis, 1984), the effect of a briefly presented masked prime on the subsequent processing of a continuously presented target is monitored. The working hypothesis when forward masked priming is used is that the processing carried out on the prime is transferred across to the target. Since forward masking reveals how the structural properties of the prime develop in time to affect the recognition of the target, experimenters typically measure latencies of lexical decision to targets that are orthographically or phonologically similar to the primes. For example, using forward masking, Ferrand and his colleagues (e.g., Ferrand \& Grainger, 1992, 1993, 1994; Grainger \& Ferrand, 1996) attempted to separate the effect of orthographic overlap from that of phonological

The reported experiments were part of the master's thesis submitted by O.Y. to the Department of Psychology. This study was supported in part by Israel Academy of Science Grant $94-00056$ and in part by National Institute of Child Health and Human Development Grant HD01994. Correspondence concerning this article should be addressed to R. Frost, Department of Psychology, Hebrew University, Jerusalem, 91905 Israel (e-mail: frost@pluto.mscc.huji.ac.il). overlap in French. They found that orthographic and phonological priming effects are independent of each other and that orthographic activation generally precedes phonological activation.

A different experimental approach is used in the backward masking paradigm (e.g., Berent \& Perfetti, 1995; Perfetti, Bell, \& Delaney, 1988; Tan \& Perfetti, 1999). In this paradigm, a target word is presented for a very short duration (usually $15-30 \mathrm{msec}$ ). The target word is followed (i.e., masked) by a pseudoword that appears for $15-60 \mathrm{msec}$ and is then replaced by a simple pattern mask. The pseudoword that masks the target can be phonemically similar to the target, graphemically similar, or a control mask. The subjects' task is to report in writing what they have perceived. Typically, subjects do not have any conscious recollection of the nonword mask. Despite this, the nonword mask still exerts some influence on the detection of the target. This is because the short exposures characteristic of the masking paradigm allow the on-line processing of the nonword masks to merge with the incomplete processing of the word targets, thereby reinstating some of their properties. Thus, in contrast to the forward masking technique, backward masking examines the very early time frame in which the properties of the mask can be used to complete the partial information extracted from the target. Typically, exposure durations in backward masking experiments are shorter than those in forward masking experiments (often 14 or $28 \mathrm{msec}$ ).

Perfetti and his colleagues consistently found that nonwords that were homophonic to the targets they masked produced better identification rates than did graphemically similar controls (Berent \& Perfetti, 1995; Perfetti \& Bell, 1991; Perfetti et al., 1988; and see Tan, Hoosain, \& Siok, 1996, and Tan \& Perfetti, 1998, for parallel results in Chinese). This outcome suggests that the phonological information extracted from the masks contributed to 
the reinstatement of the phonological properties of the targets. Thus, typically, in the backward masking paradigm, the evidence for (or against) prelexical phonological recoding is inferred from the superior (or nonsuperior) detection in the homophonic condition, relative to the orthographic control.

Although the backward masking paradigm was originally used to demonstrate the existence (e.g., Perfetti et al., 1988) or nonexistence (e.g., Verstaen, Humphreys, Olson, \& d'Ydewalle, 1995) of early phonological computations, some recent studies have examined the nature and time course of the computed phonological code. Along with this experimental approach, Berent and Perfetti (1995) found that in English, consonantal information is computed first to provide a skeletal impoverished phonological structure. Only at a second cycle is the vowel information computed and incorporated into the skeletal phonological code to produce a fully specified phonetic structure. Recently, Tan and Perfetti (1999) suggested that phonological and graphemic similarities between targets and masks have different effects on word identification in English at different time courses. Whereas graphemic masks reinstated the targets better than did homophonic masks at $28 \mathrm{msec}$, the opposite pattern emerged at the longer exposure duration of $42 \mathrm{msec}$.

In the present context, Hebrew provides a particularly interesting case for examining the role and time course of prelexical computation of phonology. Hebrew is considered a deep orthography (Frost, Katz, \& Bentin, 1987; Katz \& Frost, 1992), in which letters represent mostly consonants, whereas most of the vowels can optionally be superimposed on the consonants as diacritical marks (points). The diacritical marks are omitted from most adult reading material. However, some vowels (mainly, $/ \mathrm{o} /, / \mathrm{u} /$, and $/ \mathrm{i} /$ ) may be represented in print not only by points, but also by letters. In addition, the depth of Hebrew orthography is evident in yet another feature. Several consonants (mainly, /k/,/t/, /x/,/v/, and glottal/a/), have two letters representing them. ${ }^{1}$ These letters depicted in ancient Hebrew a phonetic distinction that is absent in modern Hebrew. This feature is of immediate relevance to the backward masking paradigm, because Hebrew pseudohomophones can be created by interchanging these consonantal letters.

In a recent study, Gronau and Frost (1997) employed backward masking to map the early computation of printed information in Hebrew. Gronau and Frost masked their target words not only by homophonic masks, but also by phonologically similar or dissimilar masks. The homophonic masks were created by interchanging two letters representing the same phoneme (e.g., the letters $\boldsymbol{\Omega}$ and $\checkmark$ representing the phoneme/t/). Phonologically similar masks were created by replacing a consonant in the target with another consonant in the mask. Phonologically dissimilar masks were created by replacing a consonant letter with a vowel letter, thereby creating a nonword with a distinctively different phonemic structure. Gronau and Frost found that phonological similarity between masks and targets affected detection in a nonlinearfashion: No dif- ferences were found between homophonic and phonologically similar masks, whereas phonologically dissimilar masks hindered identification dramatically. The identical performance in the homophonic and the phonologically similar conditions suggested that representations computed in brief exposures are coarse-grained and not detailed enough to capture fine phonetic differences. At this time course, small alterations in phonological structure (e.g., /kapit/vs. /kapiz/) were not detected by the cognitive system.

Focusing on phonological computations, the above studies, however, did not examine the parallel impact of orthographic similarity or dissimilarity on the detection of the masked printed targets. This issue is of special theoretical importance, given current debates concerning the exact time course in which orthographic and phonological structure constrain the selection of lexical candidates for lexical access (see Frost, 1998, for a discussion). The present study takes a step in this direction by examining the phonological and orthographic structures that are computed from print over different time courses. Typically, experiments using backward masking in English compared performance for homophonic and graphemic masks (e.g., Tan \& Perfetti, 1999). In Hebrew, on the other hand, the phonological and orthographic similarity between masks and targets can be independently manipulated by changing different letters. For example, the word כפית (/kapit/, printed in unpointed Hebrew using only four letters CPIT, since the first vowel/a/ is not present in the printed form) can be masked by פפיט, מפיט טיט., but also by masks are pronounced/kapit/, but in the first, only one homophonic letter is changed (the final letter $\boldsymbol{\Omega}$ is replaced by $\mathbf{v}$; Hebrew is read from right to left, and the final letter is the left-most letter), whereas in the second, the initial (rightmost) letter $\boldsymbol{J}(/ \mathrm{k} /)$ is also replaced by its homophonic letter p. Because the changed letters keep the word's phonological structure intact, this manipulation creates an increasing graphemic dissimilarity between targets and masks while preserving their phonemic representation intact. Thus, Hebrew provides a unique opportunity to systematically manipulate orthographic variation between homophonic targets and masks. Similarly, replacing a vowel letter by a consonant letter and vice versa [e.g., replacing the vowel letter " $(/ \mathrm{i} /)$, by the consonant letter $\top$ $(/ \mathrm{z} /)]$ serves to create increasing phonological dissimilarity between masks and targets while preserving their orthographic similarity, since only one letter is replaced. Thus, the two masks כיפ מדת מית differ from the target כפית (kapit/) by a single letter. But whereas the former preserves the phonological structure of the target, the latter would be read as / kapezet/ differing from the target significantly. ${ }^{2}$

In the brief durations typical of masked presentations, both the orthographic and the phonological properties of the targets and the masks are computed and encoded. However, the beneficial effect of masks in reinstating the targets arises from the merging of similar structural properties which are encoded first for the targets and then for the masks. These structural, or form, properties can be ei- 
ther phonological or orthographic. The question of interest is how the beneficial effects of identical phonological forms interact with increasing orthographic dissimilarity and how the beneficial effects of orthographic similarity interact with increasing phonological dissimilarity. These independent effects are examined at short and longer exposure durations. One possible answer is that increasing orthographic dissimilarity between targets and masks exerts its effect on target detection only at a later phase of print processing. Such an outcome would be more consistent with theories assuming a relatively late orthographic postlexical check (e.g., Lukatela \& Turvey, 1994a, 1994b). In contrast, it may be found that increased orthographic dissimilarity affects the earlier phase of print processing. Similarly, whereas traditional dual-route models regard phonological computation as slower than visual orthographic encoding and, therefore, consider the word's phonology as a secondary source of constraint on lexical access, strong phonological models of visual word recognition (e.g., Berent \& Perfetti, 1995; Frost, $1995,1998)$ present an opposing view. Thus, our investigation was aimed at examining the possible early or late constraints that orthographic and phonological structure imposes on the process of lexical access, using the unique characteristics of Hebrew.

\section{METHOD}

\section{Subjects}

Eighty-eight subjects from the Hebrew University, all native speakers of Hebrew, participated in the experiment. Forty-four were tested at the brief exposure, and 44 at the longer exposure.

\section{Stimuli and Design}

Forty-eight target Hebrew words, three to five letters long, containing three to six phonemes, were employed. The words were presented unpointed but were all unambiguous, since they could be read as meaningful words in only one way. Each target could be masked by four possible masks: (1) a control mask that differed from the target in all of its letters, (2) a phonologically dissimilar graphemic mask, in which a vowel letter was replaced by a consonant letter to create a nonword differing significantly from the target in its phonemic structure, yet preserving the same graphemic similarity to the target as the homophonic masks, (3) a homophonic mask in which one consonant letter of the target was replaced by the homophonic letter representing the same phoneme, and (4) a homophonic mask in which two consonant letters of the target were replaced by two homophonic letters representing the same phonemes. The position of the substituted letters within the target words was balanced so they could be initial, middle, or final. Table 1 presents an example of the stimuli employed in each of the five experimental conditions.

The 48 target words were divided into four lists, each list containing 12 words in each condition. The stimuli were rotated within the four conditions in each list by a Latin-square design. Subjects were randomly assigned to the short or the longer exposure experiment, as well as to each of the four lists, allowing each subject to provide data points in each condition, yet avoiding stimulus repetition effects.

\section{Procedure and Apparatus}

The experiment was conducted on an IBM 486 computer. The software used for presentation of the stimuli was the DMASTR dis-
Table 1

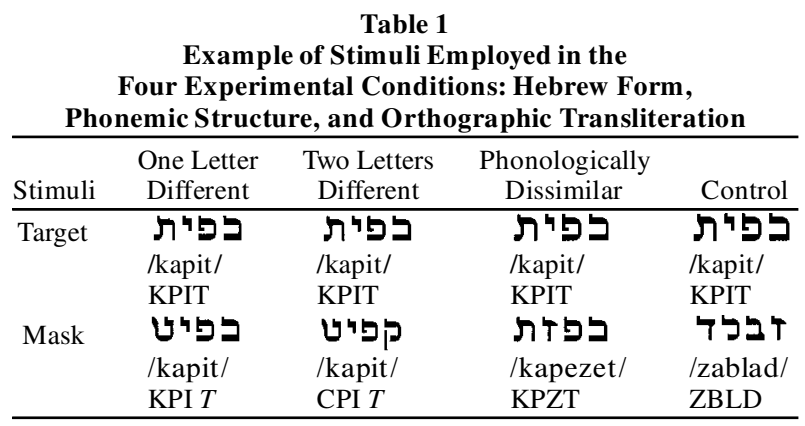

Note-The English orthographic transliteration represents the printed letters given the unpointed Hebrew print. $\mathrm{C}$ and $\mathrm{K}, \mathrm{T}$ and $T$ are the two homophonic letter pairs representing the phonemes $/ \mathrm{k} /$ and $/ \mathrm{t} /$, respectively.

play system developed by K. I. Forster and J. C. Forster at the University of Arizona. Each trial consisted of three visual events. The first was the target word appearing for $14 \mathrm{msec}$ in the shorter exposure condition and for $28 \mathrm{msec}$ with the longer exposure. ${ }^{3}$ The target was immediately followed by the nonword mask presented for $14 \mathrm{msec}$ in the shorter exposure condition and $28 \mathrm{msec}$ in the longer exposure condition. The nonword mask was, in turn, immediately followed by a pattern mask, which remained on the screen until the next trial. All the visual stimuli were centered in the viewing screen and were superimposed on the preceding stimuli. Although only one Hebrew square font was employed, two versions of this font, which differed in their relative size, were used. ${ }^{4}$ Targets were always presented in the smaller font (20\% smaller than the masks). This guaranteed complete visual masking of the targets by the masks and also made the targets and the masks physically distinct stimuli.

The subjects were tested in a dimly lit room and were seated $70 \mathrm{~cm}$ from the computer screen. When they were ready, they initiated the presentation of each trial by pressing the space bar. After each presentation, they were required to write on a response sheet the word that they had perceived. After writing the word they had identified, they again pressed the space bar to initiate the onset of the next trial. After 16 practice trials, all 48 experimental trials were presented in one block.

\section{RESULTS}

The mean detection rates of words in each experimental condition were calculated for each subject. One word was discarded from the analysis because of unexplained very low detection rates (close to zero percent detection across all subjects). Detection scores are presented in Figure 1. As can be seen from the figure, there was a general effect of exposure duration. This effect is obviously expected, and longer exposures yielded superior performance. We were concerned, however, with the relative contribution of orthographic and phonological dissimilarity at the shorter and longer exposures. Figure 1 shows that orthographic dissimilarity hindered performance at both exposure durations despite the homophonic nature of the mask. Thus, changing two homophonic letters always resulted in lower detection scores than did changing only one homophonic letter. This trend did not interact with exposure duration, and the detrimental effect of orthographic dissimilarity was virtually identical at the 
$14 \mathrm{msec}$

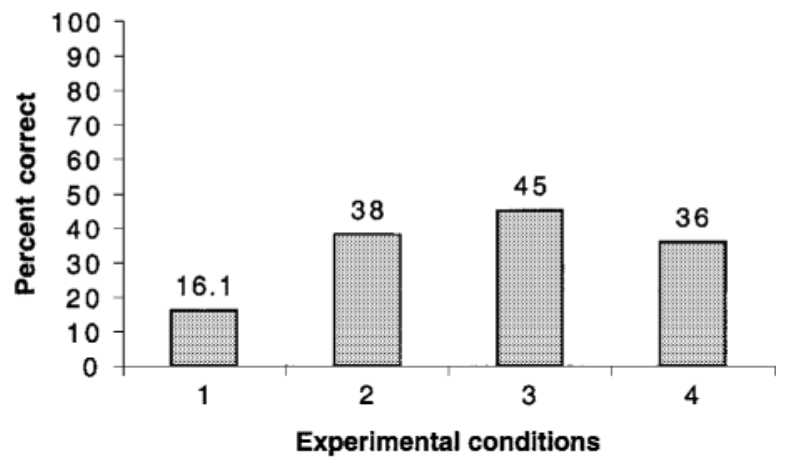

$28 \mathrm{msec}$

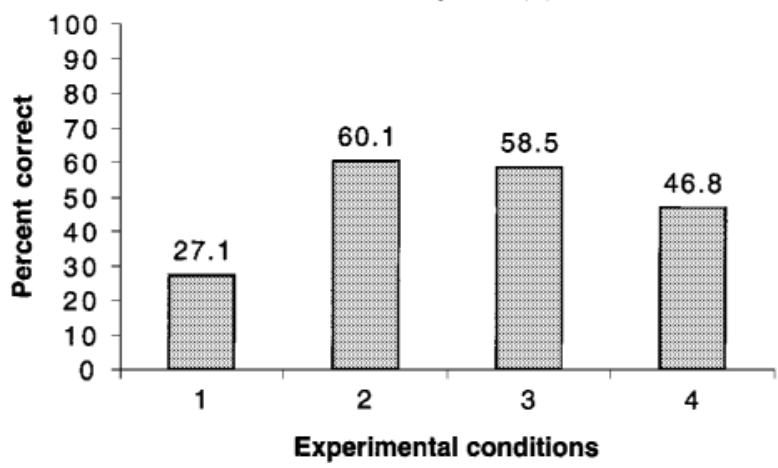

Figure 1. Percentage correct of target recognition in the four experimental conditions: (1) control, (2) phonologically dissimilar, (3) homophonic, one letter different, and (4) homophonic, two letters different.

shorter and the longer durations. In contrast, the effect of phonologicaldissimilarity was apparent only at the shorter duration.

Given the different effects of mask type at the short and long exposures, separate analyses by subjects $\left(F_{1}\right)$ and by items $\left(F_{2}\right)$ were conducted for the two exposure durations. The effect of masked type was significant at the shorter duration $\left[F_{1}(3,43)=42.8, p<.001 ; F_{2}(3,46)=27.4\right.$, $p<.001]$. Planned comparisons revealed that the difference between the one-letter-different and the two-lettersdifferent homophonic masking conditions was signifi$\operatorname{cant}\left[F_{1}(1,43)=11.5, p<.001 ; F_{2}(1,46)=7.3, p<.008\right]$. Similarly, the difference between the one-letter-different homophonic mask and the phonologicallydissimilar mask was significant by subjects and by items $\left[F_{1}(1,43)=6.7\right.$, $\left.p<.01 ; F_{2}(1,46)=4.3, p<.04\right]$.

For the longer duration, the effect of mask type was significant $\left[F_{1}(3,43)=71.9, p<.001 ; F_{2}(3,46)=34.7\right.$, $p<.001]$. Planned comparisons revealed that the difference between the one-letter-different and the two-lettersdifferent homophonic masking conditions was significant $\left[F_{1}(1,43)=22.5, p<.001 ; F_{2}(1,46)=10.3, p<.002\right]$. However, in contrast to the shorter exposure duration, there was no difference between the one-letter-different homophonic mask and the phonologically dissimilar mask $\left(F_{1}\right.$ and $\left.F_{2}<1.0\right)$.
To combine the data of the two exposure durations in one analysis of variance design, variation in the baseline detection rate in the different exposure conditions was eliminated by computing the difference scores between the control condition and the other masking conditions for each exposure duration. As was expected, this procedure neutralized the overall better detection at the longer exposure duration, and the main effect of duration did not reach significance $\left[F_{1}(1,86)=3.2, p<.07 ; F_{2}(1,92)=\right.$ $1.1, p<.3]$. The main effect of mask type was significant $\left[F_{1}(2,172)=17.6, p<.001 ; F_{2}(2,184)=9.7, p<.001\right]$. Finally, the interaction of duration and mask type was significant $\left[F_{1}(2,172)=4.6, p<.02 ; F_{2}(2,184)=2.8\right.$, $p<.06]$. Figure 2 presents the relative increase of masking efficiency of the three masks at the different durations. The figure clearly demonstrates that the negative impact of phonological dissimilarity is apparent only at the shorter exposure duration. In this condition, there was a marked difference between the homophonic mask and the phonologically dissimilar mask, even though they both differed from the target by one letter. Interestingly, at the shorter duration, one-letter-different but phonologically dissimilar masks produced detection scores that were similar to the scores obtained with masks differing from the target by two letters. In contrast, at the longer duration, the interference effect of phonological dissimilarity seems to vanish. Performance of homophonic and phonologically dissimilar masks was virtually identical.

\section{DISCUSSION}

Our results clearly show that despite the complete phonological overlap between targets and masks, changing one or two letters in the homophonic mask affected performance significantly. Thus, the probability of detecting targets masked by homophonic masks in which two letters were altered was significantly lower than the probability of detecting targets masked by homophones in which only one letter was altered. Moreover, this robust effect was independent of exposure duration, since it was almost identical in size at the shorter and the longer durations. This outcome suggests that orthographic structure poses a very early and continuous source of constraint on lexical access. Similar results were obtained in French by using forward masking with the lexical decision task (e.g., Ferrand \& Grainger, 1992, 1993, 1994) and in English by using the fast-priming paradigm (Lee, Rayner, \& Pollatsek, 1999).

Turning to the impact of phonological structure, the pattern of results seems to be more complex, since our account needs to consider the time course of computation. At the shorter exposure, altering the phonological structure of the mask had a dramatic impact on performance. In this condition, both the one-letter-different and the phonologically dissimilar masks differed from the target by one letter. However, whereas the first mask was homophonic with the target, the second was phonologically different. Thus, differences in performance between these two conditions can be attributed solely to the phonemic 


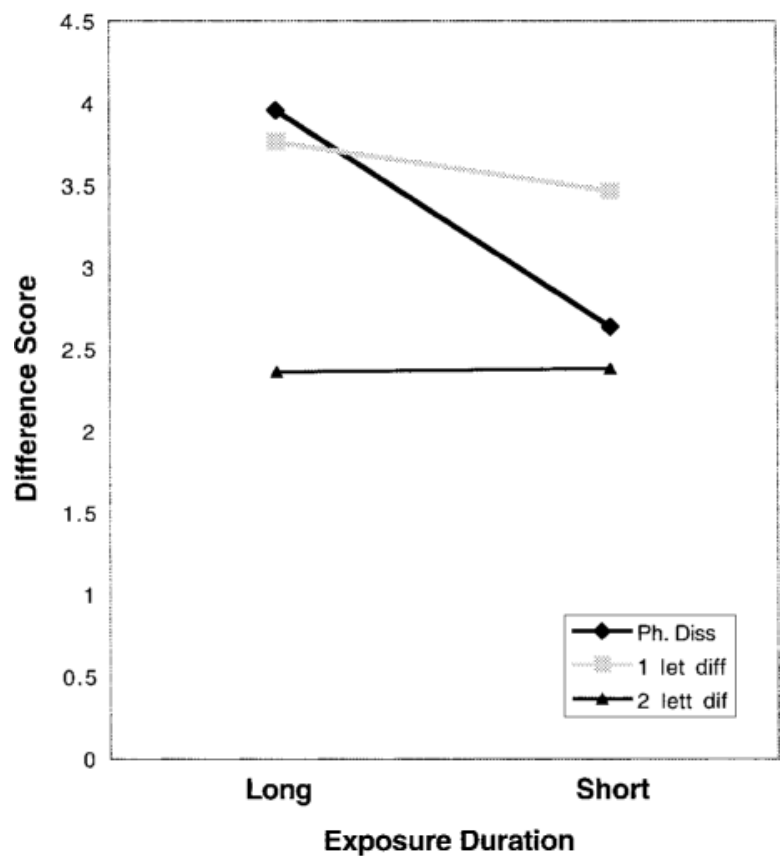

Figure 2. Mask effects in the phonologically dissimilar, homophonic-one-letter different, and homophonic-two-letters-different conditions, at short and long exposure durations. Numbers represent difference scores between the control condition and the mean number of words detected out of 12 in the three experimental conditions.

overlap between the targets and the masks. This phonological manipulation created a large drop in detection rates in the phonologically dissimilar condition, suggesting that phonological structure constrains the selection of lexical candidates at a very early stage. This phonological effect, however, dissipates at the longer exposure. At these extended exposures of masks and targets, detection scores for homophonic and phonologically dissimilar masks were virtually identical. Thus, performance at the longer stimulus onset asynchrony depended only on letter overlap, and not on the phonemic structure of the mask.

Taken together, the overall pattern of results challenges two prominent positions in word recognition research. First, according to traditional dual-route models, phonological recoding involves slow computational processes, and its output lags, therefore, behind the faster visualorthographic computation (e.g., Paap \& Noel, 1991; Seidenberg, 1992). These conclusions are supported by several studies by Ferrand and Grainger, who used the forward masking paradigm to independently manipulate orthographic and phonological similarity between primes and targets, in time courses that varied from 14 to $100 \mathrm{msec}$ (e.g., Ferrand \& Grainger, 1992, 1993, 1994; Grainger \& Ferrand, 1996). Ferrand and Grainger have consistently found that phonological encoding lagged behind visualorthographic activation. Our findings demonstrate an opposite pattern: Phonological structure poses very early sources of constraints on lexical access but seems ineffective at later stages. This conclusion fits best with the strong phonologicaltheory of visual word recognition (e.g., Frost, 1998).

One possible account for the discrepant results reported in the two studies concerns the different masking procedure, as well as the different exposure durations, that are employed in forward and backward masking. In contrast to forward masking, which examines how the properties of the prime affect the subsequent processing of the target, the backward masking paradigm examines which structural properties of the initially presented targets can be reinstated by the subsequent exposure of the mask. One immediate hypothesis to consider is that the cognitive system imposes different types of constraints on backward, as opposed to forward, transfer of information. By this view, the backward masking paradigm reveals a much more restricted time frame, in which a presented stimulus may affect the processing of a previously presented stimulus. Indeed, the range of exposure durations that is found to be effective in backward masking is limited, since performance rapidly changes from perfect accuracy to chance level. We employed the backward masking paradigm because it focuses on prelexical phonological effects at very early phases. Our results demonstrate that the phonological structure generated from the mask does not constrain the lexical selection of the target if the target has been processed long enough. Given our exposure parameters, our study cannot reveal whether the duration of the mask and the duration of the target are equally important. However, the results demonstrate that the time frame in which the phonological structure of the target can be affected by the mask is relatively narrow. Note that since subjects need to report the target, any orthographic or phonological mismatch between the mask and the target would result in an interference that will reduce the probability of correctly reporting the target. The narrow time frame, in which a phonological conflict between target and masks is effective, suggests that if the phonological structure of the target has been processed long enough, the cognitive system resists subsequent modifications by the mask. On this view, the phonological properties of the mask can no longer merge with the phonological properties of the target, because the cognitive system treats the target and the mask as two distinct events. However, since the stimuli in backward masking are printed and not spoken, orthographic structure poses a continuous source of interference. This view would attribute the effects of orthographic mismatch to visual or orthographic short-term memory, which may subsequently serve for a late spelling check.

Thus, the second implication of the present findings concerns the locus of orthographic constraints on lexical access. Proponents of the strong phonological approach to visual word recognition have suggested that although the phonological code is derived from the perceived letters, orthographic structure affects lexical selection only after the access of a phonological entry. On this view, a 
spelling check is carried out only to confirm that a correct letter sequence matches the phonemic sequence of the printed word. Orthography would then play a relatively late role in word retrieval. A model along these lines was offered by Van Orden and his colleagues (e.g., Van Orden, Johnston, \& Hale, 1988; Van Orden et al., 1990) to account for the results they obtained in the semantic categorization task and by Turvey and his colleagues, who employed masked associative priming (see Lukatela \& Turvey, 1994a, 1994b, for a detailed discussion). Our results do not seem to support this view either. At the very early duration of $14 \mathrm{msec}$, a marked difference in performance was found between the two homophonic masks that differed from the target by one or two letters. Thus, although the mask matched the phonological structure of the target, the subjects were clearly sensitive to the incorrect spelling of the mask, and their detection of the target dropped sharply. Moreover, in contrast to the constrained effect of phonologicalinterference, orthographic interference was found with both short and longer exposure durations. We should note that similar conclusions were reported by Lee et al. (1999), who employed the fastpriming paradigm in reading (see Sereno \& Rayner, 1992). In this technique, when readers fixate on a specific targetword region, a prime is encountered for a brief duration at the beginning of the fixation and is then replaced by the target. Lee et al. found significant homophone priming at durations ranging from 20 to $35 \mathrm{msec}$, whereas orthographic priming occurred at all prime durations.

It should be emphasized that the interpretation of exposure duration as reflecting the exact time course of phonological versus orthographic computation in absolute terms is partially misleading. Since the processing of the visually displayed stimuli in masking experiments depends, among other things, on the energy of the presented stimulus, such factors as luminance, brightness contrast, size of font, structure of masks, and so forth will all affect the time course of activation (e.g., Michaels $\&$ Turvey, 1979). Thus, it is not simple to compare the results obtained with similar exposure durations in different studies without taking into consideration all of these factors. Our results, however, demonstrate that the investigation of phonological and orthographic computation within a single study should not depend on taking a frozen snapshot of the cognitive system at a single time slot. Rather, experimenters should seek to monitor performance within identical experimental conditions at different time courses and/or to examine performance within a given time slot while manipulating stimulus properties. At least when the results of the present study are considered, different conclusions concerning the role of phonological computation in word recognition would be drawn if the exposure duration is very brief or if it slightly longer. This may possibly account for the numerous discrepant results obtained in studies that examined the impact of phonological manipulations under masked conditions.

In conclusion, the results of the present study demonstrate that both orthographic and phonemic structures provide constraints on the early selection of lexical can- didates during lexical access. Thus, the probability of reinstating a masked target depends on both the orthographic and the phonological overlap between the target and the mask. This suggests that the selection of lexical candidates results from cross-talk in the on-line processing of orthographic and phonological information (see Van Orden \& Goldinger, 1994, for a discussion). However, whereas phonemic structure seems to constrain lexical access at a very short time course, its role during this cross-talk diminishes at a later time course.

\section{REFERENCES}

Berent, I., \& Perfetti, C. A. (1995). A rose is a REEZE: The two-cycles of phonology assembly in reading English. Psychological Review, 102, 146-184.

Coltheart, M., Curtis. B., Atkins, P., \& Haller, M. (1993). Models of reading aloud: Dual-route and parallel-distributed-processing approaches. Psychological Review, 100, 589-608.

Ferrand, L., \& Grainger, J. (1992). Phonology and orthography in visual word recognition: Evidence from masked nonword priming. Quarterly Journal of Experimental Psychology, 45A, 353-372.

Ferrand, L., \& Grainger. J. (1993). The time course of orthographic and phonological code activation in the early phases of visual word recognition. Bulletin of the Psychonomic Society, 31, 119-122.

FerRAND, L., \& GRAINGER. J. (1994). Effects of orthography are independent of phonology in masked form priming. Quarterly Journal of Experimental Psychology, 47A, 365-382.

Forster, K. I., \& DAVIS, C. (1984). Repetition priming and frequency attenuation in lexical access. Journal of Experimental Psychology: Learning, Memory, \& Cognition, 10, 680-698.

Frost, R. (1995). Phonological computation and missing vowels: Mapping lexical involvement in reading. Journal of Experimental Psychology: Learning, Memory, \& Cognition, 21, 398-408.

Frost, R. (1998). Toward a strong phonological theory of visual word recognition: True issues and false trails. Psychological Bulletin, 123, 71-99.

Frost, R., Katz, L., \& Bentin, S. (1987). Strategies for visual word recognition and orthographical depth: A multilingual comparison. Journal of Experimental Psychology: Human Perception \& Performance, 13, 104-115.

Grainger, J., \& Ferrand, L. (1996). Masked orthographic and phonological priming in visual word recognition and naming: Cross-task comparisons. Journal of Memory \& Language, 35, 623-647.

GronaU, N., \& Frost, R. (1997). Prelexical phonologic computation in a deep orthography: Evidence from backward masking in Hebrew. Psychonomic Bulletin \& Review, 4, 107-112.

Humphreys, G. W., EvetT, L. J., \& Quinlan, P. T. (1990). Orthographic processing in visual word recognition. Cognitive Psychology, 22, 517-560.

Katz, L., \& Frost, R. (1992). Reading in different orthographies: The orthographic depth hypothesis. In R. Frost \& L. Katz (Eds.), Orthography, phonology, morphology, and meaning (pp. 67-84). Amsterdam: North-Holland.

Lee, H.-W., Rayner, K., \& Pollatsek, A. (1999). The time course of phonological, semantic, and orthographic coding in reading: Evidence from the fast-priming technique. Psychonomic Bulletin \& Review, 6, 624-634.

Lukatela, G., \& Turvey, M. T. (1990). Automatic and prelexical computation of phonology in visual word identification. European Journal of Cognitive Psychology, 2, 325-343.

Lukatela, G., \& Turvey,M. T. (1994a). Visual access is initially phonological: 1. Evidence from associative priming by words, homophones, and pseudohomophones. Journal of Experimental Psychology: General, 123, 107-128.

Lukatela, G., \& Turvey, M. T. (1994b). Visual access is initially phonological: 2. Evidence from associative priming by homophones and pseudohomophones. Journal of Experimental Psychology: General, 123, 331-353.

Michaels, C. F., \& Turvey, M. T. (1979). Central sources of visual 
masking: Indexing structures supporting seeing at a single brief glance. Psychological Research, 41, 1-61.

PAAP, K. R., \& Noel, R. W. (1991). Dual-route models of print to sound: Still a good horse race. Psychological Research, 53, 13-24.

Perfetti, C. A., \& Bell, L. C. (1991). Phonemic activation during the first $40 \mathrm{~ms}$ of word identification: Evidence from backward masking and masked priming. Journal of Memory \& Language, 30, 473-485.

Perfetti, C. A., Bell, L. C., \& Delaney, S. M. (1988). Automatic (prelexical) phonetic activation in silent word reading: Evidence from backward masking. Journal of Memory \& Language, 27, 59-70.

SeIDENBERG, M. S. (1992). Beyond orthographic depth in reading: Equitable division of labour. In R. Frost \& L. Katz (Eds.), Orthography, phonology, morphology, and meaning (pp. 85-118). Amsterdam: North-Holland.

Sereno, S. C., \& Rayner, K. (1992). Fast priming during eye fixations in reading. Journal of Experimental Psychology: Human Perception \& Performance, 18, 173-184.

TAN, L. H., Hoosain, R. \& SIOK, W. W. T. (1996). Activation of phonological codes before access to character meaning in written Chinese. Journal of Experimental Psychology: Learning, Memory, \& Cognition, 22, 865-882.

TAN, L. H., \& Perfetti, C. A. (1998). Phonological codes as early source of constraint in Chinese word identification: A review of current discoveries and theoretical accounts. In C. K. Leong \& K. Tamaoka (Eds.), Cognitive processing of the Chinese and Japanese languages (pp. 1146). Dordrecht: Kluwer.

Tan, L. H., \& Perfetti, C. A. (1999). Phonological and associative inhibition in the early stages of English word identification: Evidence from backward masking. Journal of Experimental Psychology: Human Perception \& Performance, 25, 59-69.

VAN Orden, G. C., \& Goldinger, S. D. (1994). Interdependence of form and function in cognitive systems explains perception of printed words. Journal of Experimental Psychology: Human Perception \& Performance, 20, 1269-1291.

Van Orden, G. C., Johnston, J. C., \& Hale, B. L. (1988). Word iden- tification in reading proceeds from spelling to sound to meaning. Journal of Experimental Psychology: Learning, Memory, \& Cognition, 14, 371-386.

Van Orden, G. C., Pennington, B. F., \& Stone, G. O. (1990). Word identification in reading and the promise of subsymbolic psycholinguistics. Psychological Review, 97, 488-522.

Verstaen, A., Humphreys, G. W., Olson, A., \& D'Ydewalle, G. (1995). Are phonemic effects in backward masking evidence for automatic prelexical phonemic activation in visual word recognition? Journal of Memory \& Language, 34, 335-356.

\section{NOTES}

1. The Hebrew letters $\boldsymbol{P}$ and $\boldsymbol{\Xi}$ represent the phoneme $/ \mathrm{k} /, \boldsymbol{\Omega}$ and $\boldsymbol{U}$ represent the phoneme/t/, $\mathbf{n}$ and $\boldsymbol{\Xi}$ represent /x/, $\mathbf{1}$ and $\mathbf{2}$ represent $/ \mathrm{v} /$, and $\mathbf{X}$ and represent glottal/a/.

2. Because the printed consonants can, in principle, take any of the five vowels of Hebrew, a nonword mask can be read in more than one way. Nevertheless, since all Hebrew words are composed of a root morpheme and an infixed phonological word pattern, the possible readings of a consonant string are constrained by the permissible word patterns of Hebrew and by their relative frequency.

3. Given the very sharp changes in the backward masking paradigm, from full identification of targets to no identification at all, only two exposure durations, equal to one or two refresh rates of the screen, were found to be effective and were, consequently, used in the experiment. These exposure duration parameters were set following pilot studies.

4. In English, the separation of primes and targets is often achieved by using uppercase and lowercase scripts. Although Hebrew has two forms of scripts (regular print and cursive), the cursive script is not often used in print, and we therefore adopted the manipulation of size, rather than form.

(Manuscript received December 20, 1999; revision accepted for publication August 17, 2000.) 